OPEN ACCESS

Edited by:

Michel Goldman,

Institute for Interdisciplinary Innovation in healthcare (I3h), Belgium

Reviewed by:

Elie Cogan,

Université libre de Bruxelles, Belgium

Leila Belkhir,

Cliniques Universitaires

Saint-Luc, Belgium

*Correspondence:

Manoj Prasad

manoj_prasad@nipgr.ac.in

TORCID:

Manoj Prasad

orcid.org/0000-0003-0691-0163

Specialty section:

This article was submitted to Infectious Diseases - Surveillance

Prevention and Treatment, a section of the journal

Frontiers in Medicine

Received: 30 April 2020

Accepted: 17 June 2020

Published: 05 August 2020

Citation:

Prasad A and Prasad M (2020) Single Virus Targeting Multiple Organs: What We Know and Where We Are Heading? Front. Med. 7:370 doi: 10.3389/fmed.2020.00370

\section{Single Virus Targeting Multiple Organs: What We Know and Where We Are Heading?}

\author{
Ashish Prasad and Manoj Prasad ${ }^{\star t}$ \\ National Institute of Plant Genome Research, New Delhi, India
}

COVID-19 caused by SARS-CoV-2 has already infected more than 6. 3 million people worldwide as of 1st June 2020 and caused a global medical emergency. Healthcare professionals have been struggling to devise appropriate therapeutic strategies against the virus mainly due to the diverse range of symptoms and multiple-organ failure in infected patients. Several broad-spectrum antiviral drugs are being used for treatment; however, there is yet no specific drug or vaccine against the virus. Multiple-organ failure due to hyperactivity of the immune system resulting in cytokine storms is a major reason for death among the $5 \%$ critically ill patients. In this article, we have discussed the damage caused by COVID-19 on different organs of the human body.

Keywords: SARS-CoV-2, symptoms, COVID-19, disease symptoms, multiple organ failure, health effects

\section{INTRODUCTION}

Severe acute respiratory syndrome coronavirus 2 (SARS-CoV-2), which is the causal agent of Coronavirus disease 2019 (COVID-19), is a single-stranded RNA virus with a non-segmented genome. Like other coronaviruses, four structural proteins are present in assembled viruses: membrane protein $(M)$, capsid protein $(C)$, envelope protein $(E)$, and spike glycoprotein $(S)(1,2)$. The receptor-binding domain (RBD) present within the S-glycoprotein is essential for binding to host angiotensin-converting enzyme 2 (ACE2) which serves as a receptor for viral entry. The RBD of SARS-CoV-2 has greater affinity for ACE2 than SARS-CoV (3). The presence of ACE2 throughout the human body marks tissues vulnerable to the virus. The receptor is present in the brain, liver, spleen, kidney, bone marrow, thymus, nasopharynx, oral, and nasal mucosa, lung, small intestine, stomach, colon, lymph nodes, skin, arteries, and veins (4).

Due to the lack of vaccine, immunization against the virus is not yet possible (5). Drugs like remdesivir and chloroquine are currently being used for treatment (6); however, the standard of care and use of drugs is varied between countries. To understand the biology and pathogenesis of the virus, many research papers have been published which are serving as important resources for developing diagnostics. However, the exact nature and extent of damage that the virus can cause is still not well-known. Although most of the patients develop severe respiratory problems, other organs like the brain, blood vessels, heart, gut, liver, and kidney are also susceptible to damage (Figure 1). This article summarizes the complications caused by the virus on different organs of the body. 


\section{IMMUNOLOGICAL RESPONSE TO SARS-COV-2 AND CYTOKINE STORM}

Cytokine storm is the flaring-out-of-control inflammatory response of the immune system mediated by excessive production of pro-inflammatory cytokines. The major types of cytokines include interferons, interleukins, chemokines, colony-stimulating factors, and tumor necrosis factor (7). They are involved in the initiation, amplification, and regulation of adaptive immunity (8). The damage-associated molecular patterns are recognized by epithelial cells, endothelial cells, and alveolar macrophages which start releasing cytokines like IL-6 and IP-10. T-cells, monocytes, and macrophages migrate to the site of infection and help in the clearance of infected cells (9). In a study with 20 COVID-19-recovering patients in USA, virus-specific $\mathrm{CD}^{+}$and $\mathrm{CD} 8^{+} \mathrm{T}$ cells have been identified in 100 and $70 \%$ of the convalescent patients, respectively. CD4 ${ }^{+}$ $\mathrm{T}$ cell response was robust with maximum IgA and IgG against spike and membrane protein of SARS-CoV-2 (10). In another study with COVID-19 patients in China, an early response of IgA instead of $\operatorname{IgG}$ was observed in the humoral immune response against SARS-CoV-2 (11). IgA response is also much stronger and persistent than IgM response (11). However, in some patients, a defective immune response results due to the overproduction of pro-inflammatory cytokines leading to cytokine storm (12). A higher level of cytokines leading to inflammation in multiple organs has been observed in intensive care unit (ICU) patients than in non-ICU patients (13). Multipleorgan damage is a result of the cytokine storm circulating to other organs (9).

\section{RADIOLOGICAL ASPECTS OF COVID-19}

Radiological imaging is important for the diagnosis and assessment of disease progression. Just like other pneumonias caused by other coronaviruses, asymmetric, and diffuse airspace opacities have been observed in patients (14). Transverse chest CT-scan images have revealed bilateral ground glass opacities and areas with sub-segmental consolidation (13). Certain other features like round opacities, crazy paving, and reticulation along with peripheral opacities are also common findings in chest CT scans (15). CT is recommended for recovered as well as recovering patients to evaluate long-term lung damages like fibrosis as observed in other coronavirus infections like SARS$\mathrm{CoV}$ and Middle East respiratory syndrome coronavirus (MERS$\mathrm{CoV})(16)$.

\section{EFFECT ON THE RESPIRATORY SYSTEM}

There is considerable debate on the air-borne transmission of SARS-CoV-2 with no compelling evidence (17). A report suggests that the virus can remain infectious in aerosols for up to $3 \mathrm{~h}$ (18). The nasal and throat epithelial cells serve as safe havens for the virus due to the high expression of ACE2 in these cells (19). The virus starts multiplying in these cells and, if not neutralized by the immune system, is shed in large quantity, which leads to spread to other individuals. The next target of the virus are the lungs which are also rich in ACE2 receptors (4). Type-II pneumocytes are involved in the production of alveolar surfactant, which reduces the surface tension of alveoli and airway walls preventing their collapse and allowing $\mathrm{O}_{2} / \mathrm{CO}_{2}$ exchange (20). Virus entry into these cells affects their normal physiology and associated processes, which may lead to lung collapse. In the meantime, the host cells recognize the virus/viral proteins as foreign antigens and lymphocytes start producing immunoglobulin M (IgM), IgA, and $\operatorname{IgG}(10,21)$. It has been observed that $5 \%$ of COVID19 patients become critically ill with severe pneumonia and multiple-organ damage and cytokine storm might be a possible explanation for such an observation. The dead cells and fluid left behind due to the exaggerated immune response choke the alveoli and airways, thus hampering $\mathrm{O}_{2} / \mathrm{CO}_{2}$ exchange and development of pneumonia. Chest $\mathrm{x}$-rays and CT scans reveal white opacities at regions where black space (air) should be present (13). This is due to choking of alveoli with WBCs, fluid, mucus, and dead lung cells (22).

\section{EFFECT ON KIDNEYS}

Kidneys are another target for SARS-CoV-2 due to the presence of ACE2 receptors in the proximal tubules and glomeruli (23). Proteinuria, hematuria, and elevated blood urea nitrogen and creatinine are a common observation in COVID-19 patients $(24,25)$. Plasma proteins are absorbed in the proximal tubules, and injury to these tubules results in increased protein excretion in urine (26). Hematuria can be caused by glomerular barrier disruption (27). However, proteinuria and hematuria have been described as general findings and further studies are required to shed light into their characteristics. SARSCoV-2 RNA has been detected in urine samples by RTPCR, and fully assembled viruses have been observed by transmission electron microscopy (28). Transmission by urine is another putative source of spread and should be considered while devising management strategies. Electron microscopy has also revealed the presence of viral particles in proximal tubules (29). In a renal histopathological study of 26 deceased patients in Tongji Medical College, China, revealed acute proximal tubule damage along with clusters of SARS-CoV2 in podocytes and tubular epithelium (30). The systemic immune response, cytokine storm, direct viral infection, and other hemodynamic factors in critically ill patients might be responsible for AKI leading to death of many patients due to kidney failure.

\section{EFFECT ON HEART AND BLOOD VESSELS}

Heart and blood vessels are the other hotspots of the ACE2 receptor, thus being prone to SARS-CoV-2 (4). Out of 416 patients from Renmin Hospital in Wuhan, 19.7\% suffered from severe heart injuries, highlighting the risk of heart failure associated with the infection (31). Another report suggested arrhythmia in 16 out of $36 \mathrm{ICU}$ patients in Zhongnan Hospital in Wuhan (32). Patients in the hospital were receiving antiviral 


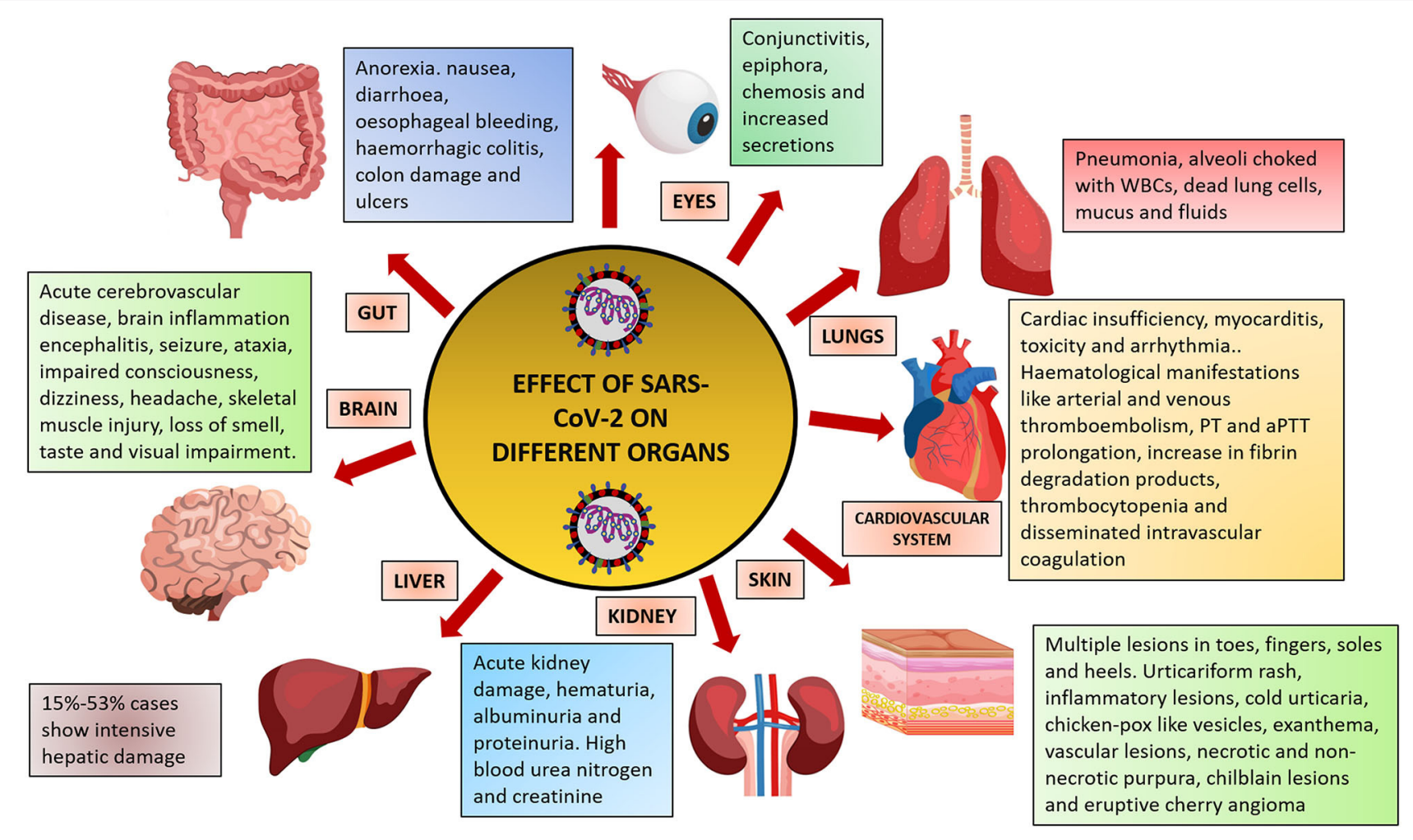

FIGURE 1 | Effect of SARS-CoV-2 infection on different organs of the human body. Figure prepared using images from freepik.com.

therapy (precise drug not specified), and antiviral drugs like hydroxychloroquine are known to promote arrhythmias (33). Myocarditis caused by inflammation of the myocardium has also been observed (34). Antiviral drugs have a very high risk potential for the heart and may lead to cardiac insufficiency, toxicity, and arrhythmia (35). Ribavirin, which is being used for treatment (36), is reported to induce sick sinus syndrome (37). Thus, it is important that the cardiovascular system is closely monitored in COVID-19 patients and special attention must be provided for its protection. A study on 184 infected patients revealed that $31 \%$ had thrombotic complications, which was very high, and arterial and venous thromboembolism due to excessive inflammation was a high risk factor (38). The major risk associated with thromboembolism is that blood clots may reach the lungs, brain, and heart and cause pulmonary embolism, stroke, and cardiac arrest, respectively. Kawasaki disease has been reported among children aged 4-11 years who were also infected with SARS-CoV-2 (39). A 6-months-old COVID-19 patient developed bulbar conjunctival infection, erythema, and edema in the upper extremities along with maculopapular rash and persistent fever. The respiratory symptoms like cough, congestion, or rhinorrhea were normal (40). Another case of a 5-years-old represented the development of incomplete Kawasaki disease (41). It is necessary to investigate the clinical course of pediatric patients with COVID-19 in association with Kawasaki disease.

\section{EFFECT ON THE GASTROINTESTINAL TRACT}

A report suggests that out of 95 patients positive for COVID19 from Sun Yat-sen University Hospital in China, 58 cases had gastrointestinal (GI) symptoms (42). Anorexia, Diarrhea, and nausea were the main symptoms among the patients, and esophageal bleeding and ulcers were reported from a patient with severe illness. However, the relation of ulcers and esophageal bleeding with SARS-CoV-2 infection is not yet clear and is just an observational study. Stomach, esophagus, duodenum, and rectum tissues have been found to be positive for the virus, indicating that these organs could also act as possible direct targets for transmission (42). ACE2 receptors are highly expressed in the small intestine, colon, and stomach, making the gastrointestinal tract highly susceptible to SARS-CoV-2 infection (4). Endoscopy has revealed extensive colon injury with hemorrhagic colitis, and stool has tested positive for viral RNA in some patients $(43,44)$. However, there is still no evidence that viral transmission can occur through stool. Healthy gut microbiota is important for proper functioning of the gut. Microbial dysbiosis has been observed in COVID-19 patients with a maximum effect on Bifidobacterium sp. and Lactobacillus $s p$. (45). It will be interesting to see whether probiotic bacteria can be used as therapeutics for controlling GI symptoms caused by the virus. However, we do not know anything about the probiotic 
use against the virus and studies in this area must be conducted to gain further insights.

\section{EFFECT ON THE CENTRAL AND PERIPHERAL NERVOUS SYSTEMS}

A case study on 214 COVID-19 patients from three special care centers of Union Hospital, Wuhan, revealed that $36.4 \%$ of the infected people had neurologic symptoms (46). The symptoms were very diverse and ranged from acute cerebrovascular disease, to seizure, to ataxia, to impaired consciousness, to dizziness, to headache, and to skeletal muscle injury. Loss of smell and taste and visual impairment were also the effects caused by the virus on the peripheral nervous system (46). The olfactory epithelium lies in the nasal cavity and is a site for viral replication and possible entry site to the brain (47). The central and peripheral nervous systems are also very rich in ACE2 abundance, making them susceptible to SARS-CoV-2 infection (4). Although shortness of breath due to lack of oxygen (silent hypoxemia) is one of the symptoms of the disease, in some cases, no such symptom has been observed although blood oxygen is critically low. Brainstem reflex is responsible for the sensing of oxygen starvation (48), and its decrease might be a possible explanation for such a manifestation. Silent hypoxemia is a difficult manifestation to control because patients might appear normal but with conditions deteriorating suddenly at a rapid pace (49). Measuring the peripheral oxygen level is very important for any COVID19 patient, as several reports suggest patients with minimal symptoms but with very critical oxygen level $(49,50)$. Brainstem dysfunction also results in altered sleep-wake cycles and compromised autonomous control of the immune, circulatory, digestive, and respiratory systems (51). Brain inflammation encephalitis accompanied with seizures has also been reported (52). SARS-CoV-2 has been detected in cerebrospinal fluid in some cases, suggesting that the neurological manifestations might be a result of the direct invasion of CNS and PNS by the virus (52). However, more studies and autopsies are required to associate the nervous system manifestations with direct viral invasion.

\section{EFFECT ON THE LIVER}

Abnormal alanine transaminase (ALT) and aspartate aminotransferase (AST) levels are an indication of liver damage. Liver damage has been observed in about 15-53\% of the cases with elevated bilirubin, AST, and ALT (53). Mild lobular and portal damage and microvascular steatosis have been observed in liver biopsies of COVID-19 deceased patients (22). The adverse effects of antiviral drugs like hydroxychloroquine, which is reported to cause acute toxic hepatitis (54) and cytokine burst, might be responsible for such high percentage of hepatic damage cases in severely ill patients.

\section{EFFECT ON THE EYES}

The occurrence of conjunctivitis has also been reported as a clinical manifestation of the infection and tears, and conjunctival fluids have tested positive for the virus in such cases (55). A doctor in China who tested positive for the virus had developed conjunctivitis before the appearance of respiratory symptoms, and it is believed that he was infected through ocular fluids (56). Some other ocular manifestations that have been observed are epiphora, chemosis, increased secretions, and conjunctival hyperemia (57). A study conducted on 56 patients in Wuhan revealed that aggravated ocular symptoms had occurred in $27 \%$ of the patients just before the onset of respiratory symptoms (58). This suggests that ocular manifestations are relatively common in COVID-19 patients and should also be considered during diagnosis (59). Long-term usage of antiviral drugs like chloroquine and hydroxychloroquine is a concern because it is known to cause retinal toxicity and retinopathy (60).

\section{EFFECT ON THE SKIN}

Some clinical manifestations have also been observed in the skin, hands, and toes 3-4 weeks after COVID-19 infection. In a study, out of six Spanish patients that had similar manifestations, two were tested positive for the virus weeks before. Multiple lesions were observed in the toes, fingers, soles, and heel (61). In another study, a 32-years-old woman from Ramon y Cajal Hospital, Madrid, Spain, developed urticariform rash 6 days after COVID-19 symptom onset. She was treated with hydroxychloroquine and azithromycin. Some other patients developed maculopapular rash (62). A nationwide study on skin manifestations across France reported several skin manifestations in COVID-19 patients. The manifestations ranged from inflammatory lesions, cold urticaria, chicken pox-like vesicles, exanthema, vascular lesions, necrotic, and non-necrotic purpura, chilblain lesions, and eruptive cherry angioma (63). There are several other reports suggesting skin manifestations in COVID-19 patients $(64,65)$. However, these are just observational reports and more studies need to be conducted to associate these observations with SARS-CoV2 infection.

\section{CONCLUSION}

According to World Health Organization, the common symptoms of the disease include dry cough, fatigue, and fever. Sore throat, nasal congestion, body aches, and pains are also common. However, several other manifestations related to the heart, lungs, liver, kidney, central nervous system, and gastrointestinal system failure is making treatment difficult for critically ill patients (66). It is still unclear whether it is the virus itself or the exaggerated immune response of the body that is causing critical illness in about $5 \%$ of the infected patients. Several clinical trials are underway, aiming at immunosuppression of COVID-19 patients to reduce cytokine storm-related manifestations resulting in 
multiple-organ damage (9). However, this reduces the natural capability of the body to fight against the virus. Antiviral drugs such as remdesivir, ritonavir, and lopinavir are also being used; however, they are known to cause severe side effects on different organs (6). The presence of ACE2 receptors throughout the human body (4) provides an opportunity for the virus to invade different organs easily and is a possible explanation why multiple-organ damage has been reported in many patients. Knowledge on the potential

\section{REFERENCES}

1. De Wit E, Van Doremalen N, Falzarano D, Munster VJ. SARS and MERS: recent insights into emerging coronaviruses. Nat Rev Microbiol. (2016) 14:523-34. doi: 10.1038/nrmicro.2016.81

2. Prasad A, Prasad M. SARS-CoV-2: the emergence of a viral pathogen causing havoc on human existence. J Genet. (2020) 99:37. doi: 10.1007/s12041-020-01205-x

3. Lan J, Ge J, Yu J, Shan S, Zhou H, Fan S, et al. Structure of the SARS-CoV-2 spike receptor-binding domain bound to the ACE2 receptor. Nature. (2020) 581:215-20. doi: 10.1038/s41586-020-2180-5

4. Hamming I, Timens W, Bulthuis MLC, Lely AT, Navis GJ, van Goor H. Tissue distribution of ACE2 protein, the functional receptor for SARS coronavirus. A first step in understanding SARS pathogenesis. J Pathol. (2004) 203:6317. doi: $10.1002 /$ path. 1570

5. Poon LLM, Peiris M. Emergence of a novel human coronavirus threatening human health. Nat Med. (2020) 26:317-9. doi: 10.1038/s41591-020-0784-9

6. Wang M, Cao R, Zhang L, Yang X, Liu J, Xu M, et al. Remdesivir and chloroquine effectively inhibit the recently emerged novel coronavirus (2019nCoV) in vitro. Cell Res. (2020) 30:269-71. doi: 10.1038/s41422-020-0282-0

7. Tisoncik JR, Korth MJ, Simmons CP, Farrar J, Martin TR, Katze MG. Into the eye of the cytokine storm. Microbiol Mol Biol Rev. (2012) 76:1632. doi: 10.1128/MMBR.05015-11

8. Ramani T, Auletta CS, Weinstock D, Mounho-Zamora B, Ryan PC, Salcedo TW, et al. Cytokines: the good, the bad, and the deadly. Int J Toxicol. (2015) 34:355-65. doi: 10.1177/1091581815584918

9. Tay MZ, Poh CM, Rénia L, Macary PA, Ng LFP. The trinity of COVID19: immunity, inflammation and intervention. Nat Rev Immunol. (2020) 20:363-74. doi: 10.1038/s41577-020-0311-8

10. Grifoni A, Weiskopf D, Ramirez SI, Mateus J, Dan JM, Rydyznski Moderbacher C, et al. Targets of T cell responses to SARS-CoV-2 coronavirus in humans with COVID-19 disease and unexposed individuals. Cell. (2020) 181:1489-501.e15. doi: 10.1016/j.cell.2020.05.015

11. Yu H, Sun B, Fang Z, Zhao J, Liu X, Li Y, et al. Distinct features of SARSCoV-2-specific IgA response in COVID-19 patients. Eur Respir J. (2020) 8:2001526. doi: 10.1183/13993003.01526-2020

12. Noroozi R, Branicki W, Pyrc K, Łabaj PP, Pośpiech E, Taheri M, Ghafouri-Fard S. Altered cytokine levels and immune responses in patients with SARS-CoV-2 infection. Cytokine. (2020) 133:155143. doi: 10.1016/j.cyto.2020.155143

13. Huang C, Wang Y, Li X, Ren L, Zhao J, Hu Y, et al. Clinical features of patients infected with 2019 novel coronavirus in Wuhan, China. Lancet. (2020) 395:497-506. doi: 10.1016/S0140-6736(20)30183-5

14. Chen N, Zhou M, Dong X, Qu J, Gong F, Han Y, et al. Epidemiological and clinical characteristics of 99 cases of 2019 novel coronavirus pneumonia in Wuhan, China: a descriptive study. Lancet. (2020) 395:507-13. doi: 10.1016/S0140-6736(20)30211-7

15. Chung M, Bernheim A, Mei X, Zhang N, Huang M, Zeng X, et al. CT imaging features of 2019 novel coronavirus (2019-nCoV). Radiology. (2020) 295:202-7. doi: 10.1148/radiol.2020200230

16. Hosseiny M, Kooraki S, Gholamrezanezhad A, Reddy S, Myers L. Radiology perspective of coronavirus disease 2019 (COVID-19): lessons from severe acute respiratory syndrome and middle east respiratory syndrome. Cardiopulm Imaging. (2020) 214:1078-82. doi: 10.2214/AJR.20.22969 organ injuries associated with COVID-19 will help in the implementation of protective measures and proper management of the disease.

\section{AUTHOR CONTRIBUTIONS}

MP conceived the idea. AP wrote the manuscript and provided revisions to the manuscript. All authors have read and approved the final version of the manuscript.

17. Lewis D. Is the coronavirus airborne? Experts can't agree. Nature. (2020) 580:175. doi: 10.1038/d41586-020-00974-w

18. Doremalen N van, Morris DH, Holbrook MG, Gamble A, Williamson BN. Aerosol and surface stability of SARS-CoV-2 as compared with SARS-CoV-1. N Engl J Med. (2020) 382:1564-7. doi: 10.1056/NEJMc2004973

19. Sungnak W, Huang N, Bécavin C, Berg M, Queen R, Litvinukova M, et al. SARS-CoV-2 entry factors are highly expressed in nasal epithelial cells together with innate immune genes. Nat Med. (2020) 579:2703. doi: 10.1038/s41591-020-0868-6

20. Zhao CZ, Fang XC, Wang D, Tang F Di, Wang XD. Involvement of type II pneumocytes in the pathogenesis of chronic obstructive pulmonary disease. Respir Med. (2010) 104:1391-5. doi: 10.1016/j.rmed.2010.06.018

21. Wölfel R, Corman VM, Guggemos W, Seilmaier M, Zange S, Müller MA, et al. Virological assessment of hospitalized patients with COVID-2019. Nature. (2020) 581:465-9. doi: 10.1038/s41586-020-2196-x

22. Xu Z, Shi L, Wang Y, Zhang J, Huang L, Zhang C, et al. Pathological findings of COVID-19 associated with acute respiratory distress syndrome. Lancet Respir Med. (2020) 8:420-2. doi: 10.1016/S2213-2600(20)30076-X

23. Mizuiri S. ACE and ACE2 in kidney disease. World J Nephrol. (2015) 4:7482. doi: 10.5527/wjn.v4.i1.74

24. Cheng Y, Luo R, Wang K, Zhang M, Wang Z, Dong L, et al. Kidney disease is associated with in-hospital death of patients with COVID-19. Kidney Int. (2020) 97:829-38. doi: 10.1016/j.kint.2020.03.005

25. Ronco C, Reis T, Husain-Syed F. Management of acute kidney injury in patients with COVID-19. Lancet Respir Med. (2020) 2019:1-5. doi: 10.1016/S2213-2600(20)30229-0

26. Bökenkamp A. Proteinuria-take a closer look! Pediatr Nephrol. (2020) 35:533-41. doi: 10.1007/s00467-019-04454-w

27. Orlandi PF, Fujii N, Roy J, Chen HY, Lee Hamm L, Sondheimer JH, et al. Hematuria as a risk factor for progression of chronic kidney disease and death: findings from the chronic renal insufficiency cohort (CRIC) study. BMC Nephrol. (2018) 19:150. doi: 10.1186/s12882-018-0951-0

28. Sun J, Zhu A, Li H, Zheng K, Zhuang Z, Chen Z, et al. Isolation of infectious SARS-CoV-2 from urine of a COVID-19 patient. Emerg Microbes Infect. (2020) 9:991-3. doi: 10.1080/22221751.2020.1760144

29. Farkash EA, Wilson AM, Jentzen JM. Ultrastructural evidence for direct renal infection with SARS-CoV-2. J Am Soc Nephrol. (2020) 5:ASN.2020040432. doi: 10.1681/ASN.2020040432

30. Su H, Yang M, Wan C, Yi L-X, Tang F, Zhu H-Y, et al. Renal histopathological analysis of 26 postmortem findings of patients with COVID-19 in China. Kidney Int. (2020) 21:1-9. doi: 10.1016/j.kint.2020.04.003

31. Shi S, Qin M, Shen B, Cai Y, Liu T, Yang F, et al. Association of cardiac injury with mortality in hospitalized patients with COVID-19 in Wuhan, China. JAMA Cardiol. (2020) 25:e200950. doi: 10.1001/jamacardio.2020.0950

32. Wang D, Hu B, Hu C, Zhu F, Liu X, Zhang J, et al. Clinical characteristics of 138 hospitalized patients with 2019 novel coronavirus-infected pneumonia in Wuhan, China. JAMA. (2020) 323:1061-9. doi: 10.1001/jama.2020.1585

33. Chen CY, Wang FL, Lin CC. Chronic hydroxychloroquine use associated with QT prolongation and refractory ventricular arrhythmia. Clin Toxicol. (2006) 44:173-5. doi: 10.1080/15563650500514558

34. Ammirati E, Wang DW. SARS-CoV-2 inflames the heart. The importance of awareness of myocardial injury in COVID-19 patients. Int J Cardiol. (2020) 311:122-3. doi: 10.1016/j.ijcard.2020.03.086 
35. Zheng YY, Ma YT, Zhang JY, Xie X. COVID-19 and the cardiovascular system. Nat Rev Cardiol. (2020) 17:259-60. doi: 10.1038/s41569-020-0360-5

36. Hung IF-N, Lung K-C, Tso EY-K, Liu R, Chung TW-H, Chu M-Y, et al. Triple combination of interferon beta-1b, lopinavir-ritonavir, and ribavirin in the treatment of patients admitted to hospital with COVID19: an open-label, randomised, phase 2 trial. Lancet. (2020) 6736:110. doi: 10.1016/S0140-6736(20)31042-4

37. Sakabe M, Yoshioka R, Fujiki A. Sick sinus syndrome induced by interferon and ribavirin therapy in a patient with chronic hepatitis C. J Cardiol Cases. (2013) 8:173-5. doi: 10.1016/j.jccase.2013.08.002

38. Klok FA, Kruip MJHA, van der Meer NJM, Arbous MS, Gommers DAMPJ, Kant KM, et al. Incidence of thrombotic complications in critically ill ICU patients with COVID-19. Thromb Res. (2020) 191:1457. doi: 10.1016/j.thromres.2020.04.041

39. Viner RM, Whittaker E. Kawasaki-like disease: emerging complication during the COVID-19 pandemic. Lancet. (2020) 6736:19-20. doi: 10.1016/S0140-6736(20)31129-6

40. Jones VG, Mills M, Suarez D, Hogan CA, Yeh D, Bradley Segal J, et al. COVID19 and kawasaki disease: novel virus and novel case. Hosp Pediatr. (2020) 10:537-40. doi: 10.1542/hpeds.2020-0123

41. Rivera-Figueroa EI, Santos R, Simpson S, Garg P. Incomplete kawasaki disease in a child with covid-19. Indian Pediatr. (2020) S097475591600179.

42. Lin L, Jiang X, Zhang Z, Huang S, Zhang Z, Fang Z, et al. Gastrointestinal symptoms of 95 cases with SARS-CoV-2 infection. Gut Immun. (2020) 69:997-1001. doi: 10.1136/gutjnl-2020-321013

43. Carvalho A, Alqusairi R, Adams A, Paul M, Kothari N, Peters S, et al. SARSCoV-2 gastrointestinal infection causing hemorrhagic colitis: implications for detection and transmission of COVID-19 disease. Am J Gastroenterol. (2020) 115:942-6. doi: 10.14309/ajg.0000000000000667

44. Xiao F, Tang M, Zheng X, Liu Y, Li X, Shan H. Evidence for gastrointestinal infection of SARS-CoV-2. Gastroenterology. (2020) 158:18313.e3. doi: $10.1053 /$ j.gastro. 2020.02 .055

45. Mak JWY, Chan FKL, Ng SC. Probiotics and COVID-19: one size does not fit all. Lancet Gastroenterol Hepatol. (2020) 5:644-5. doi: 10.1016/S2468-1253(20)30122-9

46. Mao L, Jin $\mathrm{H}$, Wang $\mathrm{M}, \mathrm{Hu} \mathrm{Y}$, Chen $\mathrm{S}$, He Q, et al. Neurologic manifestations of hospitalized patients with coronavirus disease 2019 in Wuhan, China. JAMA Neurol. (2020) 77:1-9. doi: 10.1001/jamaneurol.2020.1127

47. Butowt R, Bilinska K. SARS-CoV-2: olfaction, brain infection, and the urgent need for clinical samples allowing earlier virus detection. ACS Chem Neurosci. (2020) 11:1200-3. doi: 10.1021/acschemneuro.0c00172

48. Costa KM, Accorsi-Mendonça D, Moraes DJA, Machado BH. Evolution and physiology of neural oxygen sensing. Front Physiol. (2014) 5:302. doi: $10.3389 /$ fphys.2014.00302

49. Ottestad W, Seim M, Mæhlen JO. COVID-19 with silent hypoxemia. Tidsskr Den Nor legeforening. (2020) 140:19-21. doi: 10.4045/tidsskr.20.0299

50. Wilkerson RG, Adler JD, Shah NG, Brown R. Silent hypoxia: a harbinger of clinical deterioration in patients with COVID-19. Am J Emerg Med. (2020). doi: 10.1016/j.ajem.2020.05.044. [Epub ahead of print].

51. Benghanem S, Mazeraud A, Azabou E, Chhor V, Shinotsuka CR, Claassen J, et al. Hepatic dysfunction in critically ill patients. Crit Care. (2020) 24:5. doi: 10.1186/s13054-019-2718-9

52. Moriguchi T, Harii N, Goto J, Harada D, Sugawara H, Takamino J, et al. A first case of meningitis/encephalitis associated with SARS-Coronavirus-2. Int J Infect Dis. (2020) 94:55-8. doi: 10.1016/j.ijid.2020.03.062

53. Xu L, Liu J, Lu M, Yang D, Zheng X. Liver injury during highly pathogenic human coronavirus infections. Liver Int. (2020) 40:9981004. doi: $10.1111 /$ liv.14435
54. Abdel Galil SM. Hydroxychloroquine-induced toxic hepatitis in a patient with systemic lupus erythematosus: a case report. Lupus. (2015) 24:63840. doi: $10.1177 / 0961203314561667$

55. Xia J, Tong J, Liu M, Shen Y, Guo D. Evaluation of coronavirus in tears and conjunctival secretions of patients with SARS-CoV-2 infection. J Med Virol. (2020) 92:589-94. doi: 10.1002/jmv.25725

56. Lu CW, Liu XF, Jia ZF. 2019-nCoV transmission through the ocular surface must not be ignored. Lancet. (2020) 395:e39. doi: 10.1016/S0140-6736(20)30313-5

57. Wu P, Duan F, Luo C, Liu Q, Qu X, Liang L, et al. Characteristics of ocular findings of patients with coronavirus disease 2019 (covid19) in hubei province, China. JAMA Ophthalmol. (2020) 138:5758. doi: 10.1001/jamaophthalmol.2020.1291

58. Hong N, Yu W, Xia J, Shen Y, Yap M, Han W. Evaluation of ocular symptoms and tropism of SARS-CoV-2 in patients confirmed with COVID-19. Acta Ophthalmol. (2020) 26:10.1111/aos.14445. doi: 10.1111/aos. 14445

59. Bacherini D, Biagini I, Lenzetti C, Virgili G, Rizzo S, Giansanti F. The COVID19 Pandemic from an ophthalmologist's perspective. Trends Mol Med. (2020) 26:529-31. doi: 10.1016/j.molmed.2020.03.008

60. Marmor MF. COVID-19 and chloroquine/hydroxychloroquine: is there ophthalmological concern? Am J Ophthalmol. (2020). doi: 10.1016/j.ajo.2020.03.029. [Epub ahead of print].

61. Landa N, Mendieta-eckert M, Fonda-pascual P, Aguirre T. Chilblain-like lesions on feet and hands during the COVID-19 pandemic. Int J Dermatol. (2020) 59:739-43. doi: 10.1111/ijd.14937

62. Fernandez-Nieto D, Ortega-Quijano D, Segurado-Miravalles G, PindadoOrtega C, Prieto-Barrios M, Jimenez-Cauhe J. Comment on: Cutaneous manifestations in COVID-19: a first perspective. Safety concerns of clinical images and skin biopsies. J Eur Acad DermatolVenereol. (2020) 34:e2524. doi: $10.1111 /$ jdv. 16470

63. Bouaziz JD, Duong T, Jachiet M, Velter C, Lestang P, Cassius C, et al. Vascular skin symptoms in COVID-19: a french observational study. J Eur Acad Dermatol Venereol. (2020) 34:e252-4. doi: 10.1111/jdv. 16544

64. Magro C, Mulvey JJ, Berlin D, Nuovo G, Salvatore S, Harp J, et al. Complement associated microvascular injury and thrombosis in the pathogenesis of severe COVID-19 infection: a report of five cases. Transl Res. (2020) 220:113. doi: $10.1016 /$ j.trsl.2020.04.007

65. Marzano AV, Genovese G, Fabbrocini G, Pigatto P, Monfrecola G, Piraccini BM, et al. Varicella-like exanthem as a specific COVID-19associated skin manifestation: multicenter case series of 22 patients. J Am Acad Dermatol. (2020) 83:280-5. doi: 10.1016/j.jaad.2020. 04.044

66. Murthy S, Gomersall CD, Fowler RA. Care for critically ill patients with COVID-19. JAMA. (2020) 323:1499-500. doi: 10.1001/jama.202 0.3633

Conflict of Interest: The authors declare that the research was conducted in the absence of any commercial or financial relationships that could be construed as a potential conflict of interest.

Copyright $\odot 2020$ Prasad and Prasad. This is an open-access article distributed under the terms of the Creative Commons Attribution License (CC BY). The use, distribution or reproduction in other forums is permitted, provided the original author(s) and the copyright owner(s) are credited and that the original publication in this journal is cited, in accordance with accepted academic practice. No use, distribution or reproduction is permitted which does not comply with these terms. 